\title{
BLAST DISEASE OF BLACK GLUTINOUS RICE GERMPLASMS UNDER INOCULATION AT SEEDING AND TILLERING STAGES
}

\author{
Jetsadakorn LUANGMANEE ${ }^{1}$, Poramate BANTERNG ${ }^{1,2 *}$ and Anan WONGCHAROEN ${ }^{1}$ \\ ${ }^{1}$ Khon Kaen University, Faculty of Agriculture, Department of Plant Science and Agricultural \\ Resources, Khon Kaen, THAILAND \\ ${ }^{2}$ Khon Kaen University, Faculty of Agriculture, Plant Breeding Research Center for Sustainable \\ Agriculture, Khon Kaen, THAILAND \\ *Corresponding author: bporam@kku.ac.th
}

Received: 17.09.2015

\begin{abstract}
Black rice is an alternative source of blast disease resistance and appropriate screening method is necessary to be proposed. The objectives were to 1) evaluate leaf blast disease of different black glutinous rice genotypes, and 2) determine correlations between disease symptoms at seedling and tillering stages. Leaf blast disease for 25 black glutinous rice genotypes and 3 check genotypes were observed at Khon Kaen University, Thailand in 2013 and 2014. HY 71, Niawdam Gs.no.21629, Khaokam Gs.no.88084, KKU-GL-BL-05-003, KKU-GL-BL-05004, KKU-GL-BL-06-010 and KKU-GL-BL-06-023 were high resistant genotypes across growth stages, times of evaluation and years. Seedling and tillering stages were significantly different for severity index. Correlation coefficients between severity indices at seeding and tillering stages in 2013 and 2014 for evaluation at 7 days after inoculation (DAI) were $0.34(p<0.01)$ and $0.29(p<0.01)$, respectively, and for evaluation at 14 DAI were $0.40(p<0.01)$ and $0.41(p<0.01)$, respectively. Correlation coefficients between severity indices evaluated at 7 and 14 DAI for growth stages and years varied from 0.34 to $0.50(p<0.01)$. The results suggested that screening of leaf blast disease at only seedling stage was not enough to identify resistant genotypes.
\end{abstract}

Key Words: Breeding, Crop improvement, Pyricularia oryzae, Resistance, Screening

\section{INTRODUCTION}

Rice is an important staple food crop for many countries in the world (Chun et al., 2016). Currently, most of rice production areas in the world frequently encounter blast fungus (Pyricularia grisea Sacc. or Pyricularia oryzae or Magnaporthe grisea). Rice blast is a serious problem for rice yield reduction and it causes yield loss of about 10 to 30\% (Talbot, 2003; Skamnioti and Gurr, 2009; Spyridon et al., 2009; Bhuiyan et al., 2011).

Rice blast disease prevention can be achieved in several ways such as spraying chemicals (Theeraamphon, 2008), reduction of nitrogen fertilization, management of fertilizer according to soil fertility, control of plant population, chemical seed treatment (Yokoyama, 1981; Teng, 1994), using organic fertilizers instead of chemical fertilizers (Obilo et al., 2012), using a wind turbine (fanforced wind) to decrease the humidity in rice field (Yoshihiro et al., 2014) and the use of biological control methods such as Streptomyces sp. PM5 (Prabavathy et al.,. 2006), Bacillus licheniformis (Tendulkar et al., 2007), Pseudomonas fluorescens and Bacillus polymyxa (Karthikeyan and Gnanamanickam, 2008). However, these methods are costly and not accessible for the farmers. Genetic resistance to leaf blast disease has been reported in rice (Cécile et al., 2008). Therefore, the use of resistant varieties is a reasonable alternative means to control the disease, and it also reduces the cost of chemical application and contamination in the environment.

Glutinous rice with purple or red color in pericarp (black glutinous rice) is an alternative germplasm source for blast resistance. The purple pigment (anthocyanin: cyaniding-3-glucoside) in the husk (hull) and pericarp and gamma oryzanol from rice bran oil are advantageous antioxidants (Ryu et al., 1998; Cicero and Gaddi, 2001; Sanmuangchin et al., 2008; Boonsit et al., 2010; Bhuiyan et al., 2011; Joralee et al., 2013). Black glutinous rice is also a potential source for functional food products and the market opportunity for black glutinous rice is great as the trend for consumption is increasing. Therefore, the identification of blast resistance levels of different black glutinous rice genotypes will provide the opportunity for discovering more new resistant genotypes for rice breeding programs.

Blast disease can damage rice at any growth stage. In the vegetative growth stage, leaf blast disease normally 
occurs in rice leaves. In addition, neck blast is also found in the reproductive stage. Both leaf blast and neck blast can reduce rice yield (Hwang et al., 1987; Bonman, 1992). Assessment of leaf blast disease in rice is generally made by visual observation because it is easy. However, the resistance levels will improve as the age of the leaves increases (Kato et al., 1969; Roumen et al., 1992). The leaves are also involved in the expression of resistance. Therefore, it is necessary to evaluate the levels of resistance to leaf blast disease in different growing periods such as seedling and tillering stages.

The germ cells of leaf blast can spread to other rice cells within 2 to 6 days after exposing, and the infected plants begin to show signs of disease symptoms at about 6 days after infection. However, the duration of disease cycle is about 7 to 14 days after exposure to the leaves (Cécile et al., 2008). Both single and multiple assessments of disease resistance have been reported in previous investigations. For single evaluation, the evaluation times would be at 6 days after inoculation (DAI) (Yun Sung and Ki Deok, 2009; Zakira et al., 2009), 7 to 8 DAI (Bhuiyan et al., 2011; Vikas et al., 2011; Shirasawa et al., 2012; Aram et al., 2013a; Aram et al., 2013b) and 8 to 10 DAI (Puri et al., 2009). For multiple evaluations, the assessment of the disease was carried out at 7 DAI and repeated at 14 DAI (Zhan et al., 2012). There were different in the number of assessments and it was not conclusive. Therefore, setting the number of evaluations of blast symptom after inoculation is also the issue to find out.

This study aimed to 1) evaluate the severity index of leaf blast disease for different black glutinous rice and check genotypes at seedling and tillering stages, and 2) assess the relationship between severity indices evaluated at seedling and tillering stages. The results of this study will provide the levels of resistance to rice blast disease of tested rice genotypes. This will be valuable information for improving the resistance to rice blast disease in the future. It can also be used to help determine how to evaluate the resistance to blast disease and to increase the efficiency of rice breeding.

\section{MATERIALS AND METHODS}

Twenty five genotypes of black glutinous rice and 3 check genotypes (Table 1) were evaluated for resistance to leaf blast disease. The factorial experiment in a completely randomized design (CRD) with three replications was used. The first factor consisted of two different growth stages (seedling and tillering stages) and 28 genotypes were assigned as the second factor. Resistance to leaf blast disease were evaluated at 7 and 14 DAI under the open greenhouse at the Faculty of Agriculture, Khon Kaen University during July to October 2013 and repeated in the same month in 2014.

Table 1. Rice genotypes used in this study.

\begin{tabular}{llll}
\hline No. & Genotype & No. & Genotype \\
\hline 1. & Niawdam Gs.no.00621 & 15. & KKU-GL-BL-06-010 \\
2. & Niawdam Gs.no.09475 & 16. & KKU-GL-BL-05-011 \\
3. & Niawdam Gs.no.21427 & 17. & KKU-GL-BL-06-023 \\
4. & Niawdam Gs.no.21629 & 18. & KKU-GL-BL-06-034 \\
5. & Khaokam Gs.no.88084 & 19. & KKU-GL-BL-06-035 \\
6. & Khaokam Gs.no.87090 & 20. & KKU-GL-BL-06-038 \\
7. & KKU-GL-BL-05-001 & 21. & KKU-GL-BL-06-039 \\
8. & KKU-GL-BL-05-002 & 22. & KKU-GL-BL-06-041 \\
9. & KKU-GL-BL-05-003 & 23. & KKU-GL-BL-06-043 \\
10. & KKU-GL-BL-05-004 & 24. & KKU-GL-BL-06-050 \\
11. & KKU-GL-BL-05-005 & 25. & KKU-G1-B1-11-001 \\
12. & KKU-GL-BL-05-006 & 26. & RGDU 04285-3-3 (check) \\
13. & KKU-GL-BL-05-008 & 27. & RD6 ${ }^{1 /}$ (check) \\
14. & KKU-GL-BL-05-009 & 28. & HY 712/ (check) \\
\hline
\end{tabular}

${ }^{1 /}$ Susceptible genotype, ${ }^{2 /}$ Resistant genotype

\section{Preparation of plant materials}

The plastic pots with a diameter of $20 \mathrm{~cm}$ were loaded with dry soil of $1.5 \mathrm{~kg}$ and three pots were used in a replication. The soil was Roi Et series (fine-loamy, mixed, subactive, isohyperthermic Aeric Kandiaquults). The rice seeds of 25 genotypes were obtained from Plant Breeding Research Center for Sustainable Agriculture, Khon Kaen University, Thailand. Three check genotypes were obtained from Rice Department of Thailand (Table 1). The seeds were soaked in fresh water for 1 day before planting. In both years, the rice seeds were planted in July and in August for disease evaluation at tillering and seedling stages, respectively. Rice seedlings were thinned to obtain 3 plants per pot at 7 days after planting. Fertilizer management divided into 2 phases: 1 ) fertilizer $15-15-15$ at a rate of $25 \mathrm{~kg} \mathrm{ha}^{-1}(0.42 \mathrm{~g}$ per pot) was applied at 35 days after planting for disease evaluation at both seedling and tillering stages and 2) Fertilizer 46-0-0 at a rate of $25 \mathrm{~kg} \mathrm{ha}^{-1}(0.42 \mathrm{~g}$ per pot) was applied at 14 days after planting for disease evaluation at seedling stage and at 63 days after planting for disease evaluation at tillering stage to enhance the suitable condition for infection. 


\section{Preparation and inoculation of Pyricularia oryzae}

Pyricularia oryzae fungus that caused disease symptom in rice was collected from the rice fields in Kosum Phisai district, Maha Sarakham province, Thailand which is the hot spot for this disease. The fungus were further cultured in rice polish agar (RPA) and incubated at $28{ }^{\circ} \mathrm{C}$ for 7 to 14 days. After 7 days of incubation the fungus was pressed on the surface of the agar to induce sporulation and then it was exposed to ordinary light for 3 days. The fungus was ready for preparing inoculum. The details procedures were described previously (Mackill and Bonman, 1986).

For preparation of inoculum, the mycelium was scrapped with a glass rod and dissolved in distilled water. The spores were counted under a microscope and diluted to obtain the conidia solution at the concentration of $5 \times 10^{5}$ conidia $\mathrm{ml}^{-1}$. The conidia solution was added with Tween 20 at the concentration of $0.1 \%$. Inoculation of the conidia inoculum to the crop at seedling stage (21 days after planting) and tillering stage (70 days after planting) was achieved by using an airbrush spray system in December in both years. The plants were allowed to grow in greenhouse after inoculation.

\section{Calculation of severity index (SI)}

Leaf blast disease scores were recorded at 7 and 14 DAI in both years. The disease rating scales varied from 0 to 9 points based on the symptoms and severity (Table 2). Calculation of the severity index values was done by following the formula as follows (Pattama, 1998),

$\mathrm{SI}=[\Sigma(\mathrm{Ni} \times \mathrm{Vi}) /(\mathrm{V} \times \mathrm{N})] \times 100$,

where $\mathrm{Ni}=$ number of plants in each level, $\mathrm{Vi}=$ rating levels from evaluation, $\mathrm{V}=$ highest score in the evaluation and $\mathrm{N}=$ number of plants used for testing. The severity indices used to deploy a level of resistance were $0=$ very resistance (VR), $1-20 \%=$ resistance $(\mathrm{R}), 21-40 \%=$ moderate resistance (MR), 41-60\% $=$ moderate susceptible (MS), $61-80 \%=$ susceptible $(\mathrm{S})$, and $81-100 \%$ $=$ very susceptible $(\mathrm{VS})$.

Table 2. Disease score ratings of blast disease for lesion types.

\begin{tabular}{|c|c|}
\hline Score & Predominant lesion type \\
\hline 0 & No lesions observed \\
\hline 1 & Small brown speck of pinpoint size or larger $(0.5 \mathrm{~mm})$, brown specks without sporulating center \\
\hline 3 & $\begin{array}{l}\text { Small, roundish to slightly elongated necrotic sporulating spots, about } 1-2 \mathrm{~mm} \text { in diameter with a distinct } \\
\text { brown margin or yellow halo }\end{array}$ \\
\hline 5 & Narrow or slightly ellipitical lesion, $1-2 \mathrm{~mm}$ in breadth, more than $3 \mathrm{~mm}$ long with a brown margin \\
\hline 7 & Broad spindle-shaped lesion with yellow, brown, or purple margin \\
\hline 9 & Rapidly coalescing small, whitish, grayish, or bluish lesions without distinct margins \\
\hline
\end{tabular}

Source: International Rice Research Institute (1996)

\section{Statistical analysis}

Analysis of variance for data investigated was performed according to a factorial experiment with arrangement of the treatments in a completely randomized design. Separated analysis for each year was performed, and error variances were tested for homogeneity. The data with variance homogeneity were combined and analyzed. The correlation coefficients between severity indices evaluated at seedling and tillering stages and between the evaluations at 7 and 14 DAI for 2013 and 2014 were calculated (Gomez and Gomez, 1984). The analysis of variance was done in MSTAT-C Version 1.42 program (Freed and Nissen, 1992).

\section{RESULTS}

Analysis results for the leaf blast disease (Pyricularia oryzae) after inoculation into 25 genotypes of black glutinous rice and 3 check genotypes indicated that two experimental years were significantly different $(p<0.01)$ for severity index evaluated at $7 \mathrm{DAI}$, but not for the index evaluated at 14 DAI. In addition, year accounted for 19.8 and $1.3 \%$ of total variation for the evaluation at 7 and 14 DAI, respectively (Table 3).
There were also significant differences between severity indices at seedling and tillering stages for both evaluations at $7(p<0.01)$ and 14 DAI $(p<0.05)$ (Table 3$)$. This indicated the different expression of resistance levels for leaf blast in two different growth stages. However, growth stages accounted for 3.4 and $0.8 \%$ of total variation for the evaluation at 7 and 14 DAI, respectively. Considering the correlation coefficients between severity indices at seedling and tillering stages, the coefficients for evaluation at 7 and 14 DAI in 2013 were $0.34(p<0.01)$ and $0.40(p<0.01)$, respectively, and the coefficients in 2014 were $0.29(p<0.01)$ and $0.41(p<0.01)$, in respective order (Table 4). Although most correlation coefficients were positive and significant, the values were rather low, showing the weak relationship between the data.

Comparing the severity index among 28 genotypes, the results from combined analysis of variance for two experimental years showed significant difference $(p<0.01)$ for both evaluations at 7 and 14 DAI. The results also indicated that genotypes accounted for 25 and $23.3 \%$ of total variation for the evaluation at 7 and 14 DAI, respectively (Table 3). Moreover, the analysis of variance for individual experimental year indicated that there were 
generally significant differences among 28 genotypes, except an analysis for the inoculation at seedling stage, the evaluation at 14 DAI and in 2013 (Table 5 and Table 6). Based on the actual percentage of severity index, HY 71 was identified as high resistant genotypes for both inoculations at seedling and tillering stages in 2013 (Table 5). For 2014, HY 71 and Khaokam Gs.no.88084 were high resistant genotypes for the inoculation at seedling stage, whereas KKU-GL-BL-05-004, KKU-GL-BL-05005, KKU-GL-BL-05-009 and RGDU 04285-3-3 were high resistant genotypes for the inoculation at tillering stage (Table 6). RD6, KKU-GL-BL-06-041, KKU-GLBL-06-043, KKU-GL-BL-06-034, KKU-GL-BL-06-035 and KKU-GL-BL-06-038 were the susceptible genotypes in 2013, and RD6 was also the susceptible genotype in 2014.

Table 3. Mean squares and percentages of sum squares from combined analysis of variance for severity index of tested rice genotypes at two growth stages in 2013 and 2014.

\begin{tabular}{|c|c|c|c|c|c|c|c|}
\hline \multirow{3}{*}{ Source of variation } & \multirow{3}{*}{ df } & \multicolumn{6}{|c|}{ Severity index } \\
\hline & & \multicolumn{3}{|c|}{7 DAI } & \multicolumn{3}{|c|}{14 DAI } \\
\hline & & MSE & & $\% \mathrm{SS}$ & MSE & & $\% \mathrm{SS}$ \\
\hline Year & 1 & 11941.9 & $* *$ & 19.8 & 720.2 & ns & 1.3 \\
\hline Error & 4 & 107.6 & & 0.7 & 1315.1 & & 9.4 \\
\hline Growth stage & 1 & 2054.1 & $* *$ & 3.4 & 450.7 & $*$ & 0.8 \\
\hline Growth stage $\times$ Year & 1 & 825.5 & $* *$ & 1.4 & 172.0 & ns & 0.3 \\
\hline Genotype & 27 & 558.4 & $* *$ & 25.0 & 484.9 & $* *$ & 23.3 \\
\hline Genotype $\times$ Year & 27 & 138.4 & $*$ & 6.2 & 288.1 & $* *$ & 13.8 \\
\hline Growth stage $\times$ Genotype & 27 & 138.2 & $*$ & 6.2 & 138.1 & ns & 6.6 \\
\hline Growth stage $\times$ Genotype $\times$ Year & 27 & 175.7 & $* *$ & 7.9 & 134.2 & ns & 6.5 \\
\hline Error & 220 & 80.8 & & 29.5 & 97.1 & & 38.0 \\
\hline $\mathrm{CV}(\%)$ & & 24.07 & & & 26.13 & & \\
\hline
\end{tabular}

DAI = days after inoculation, MSE = mean square error, $\% \mathrm{SS}=$ percentage values $(\%)$ for sum squares per total sum of squares, ns $=$ nonsignificance in statistics, $*$ and $* *=$ Statistical significance at alpha level 0.05 and 0.01 , respectively

Table 4. Correlation coefficients between severity indices evaluated at seedling and tillering stages ( $\mathrm{n}=84)$.

\begin{tabular}{|c|c|c|c|c|c|c|}
\hline \multirow{2}{*}{ Year } & \multirow{2}{*}{ Growth stage } & \multirow{2}{*}{ Evaluation date } & \multicolumn{2}{|l|}{2013} & \multicolumn{2}{|l|}{2014} \\
\hline & & & $7 \mathrm{DAI}$ & $14 \mathrm{DAI}$ & $7 \mathrm{DAI}$ & $14 \mathrm{DAI}$ \\
\hline 2013 & Seedling stage & $7 \mathrm{DAI}$ & $0.34^{* *}$ & & & \\
\hline 2014 & Seedling stage & $\begin{array}{l}14 \mathrm{DAI} \\
7 \mathrm{DAI} \\
14 \mathrm{DAI}\end{array}$ & & $0.40^{* *}$ & $0.29^{* *}$ & $0.41^{* *}$ \\
\hline
\end{tabular}

DAI $=$ days after inoculation, ${ }^{* *}=$ Statistical significance at alpha level 0.01

The interaction between growth stage and year was recorded for the evaluations at $7 \mathrm{DAI}(p<0.01)$, but not for the evaluation at 14 DAI (Table 3). However, interaction variation accounted for a small portion of total variation for severity index evaluated at 7 DAI $(1.4 \%)$. This indicated that there were different effects of years for severity index of leaf blast evaluated at 7 DAI in each growth stage of rice and the effects of years in each growth stage were similar for evaluated at 14 DAI. Interaction between genotype and year was significant for both evaluation at $7(p<0.05)$ and 14 DAI $(p<0.01)$, this indicated that the expression the resistance levels of genotypes in each year when evaluated at 7 and 14 DAI were different.
The results also showed the interaction between growth stage and genotype for the evaluation at $7 \mathrm{DAI}$ $(p<0.05)$, but not for the evaluation at 14 DAI. Therefore, expressions of genotypes in each growth stage for the evaluation at 14 DAI were similar. Moreover, the correlation coefficients between the severity indices evaluated at 7 and 14 DAI for seedling and tillering stages in 2013 were $0.50(p<0.01)$ and $0.34(p<0.01)$, respectively, and the correlation coefficient between the severity indices of both seedling and tillering stages in 2014 was $0.50(p<0.01)$ (Table 7). 
Table 5. Means for severity index and resistance levels of tested rice genotypes in seedling and tillering stages and under evaluated at 7 and $14 \mathrm{DAI}$ in 2013.

\begin{tabular}{|c|c|c|c|c|c|c|c|c|}
\hline \multirow{3}{*}{ Genotype } & \multicolumn{4}{|c|}{ Seedling stage } & \multicolumn{4}{|c|}{ Tillering stage } \\
\hline & \multicolumn{2}{|c|}{7 DAI } & \multicolumn{2}{|c|}{14 DAI } & \multicolumn{2}{|c|}{7 DAI } & \multicolumn{2}{|c|}{14 DAI } \\
\hline & $\% \mathrm{SI}^{3 /}$ & Level & $\% \mathrm{SI}^{3 /}$ & Level & $\% \mathrm{SI}^{3 /}$ & Level & $\% \mathrm{SI}^{3 /}$ & Level \\
\hline Niawdam Gs.no.00621 & $37^{\mathrm{B}-\mathrm{D}}$ & MR & 23 & MR & $40^{\mathrm{A}-\mathrm{E}}$ & MR & $49^{\mathrm{AB}}$ & MS \\
\hline Niawdam Gs.no.09475 & $37^{\mathrm{B}-\mathrm{D}}$ & MR & 30 & MR & $54^{\mathrm{A}}$ & MS & $35^{\mathrm{A}-\mathrm{D}}$ & MR \\
\hline Niawdam Gs.no.21427 & $36^{\mathrm{B}-\mathrm{D}}$ & MR & 34 & MR & $41^{\mathrm{A}-\mathrm{E}}$ & MS & $39^{\mathrm{A}-\mathrm{C}}$ & MR \\
\hline Niawdam Gs.no.21629 & $32^{\mathrm{B}-\mathrm{D}}$ & MR & 43 & MS & $38^{\mathrm{B}-\mathrm{E}}$ & MR & $34^{\mathrm{A}-\mathrm{D}}$ & MR \\
\hline Khaokam Gs.no. 88084 & $34^{\mathrm{B}-\mathrm{D}}$ & MR & 31 & MR & $40^{\mathrm{A}-\mathrm{E}}$ & MR & $17^{\mathrm{D}}$ & $\mathrm{R}$ \\
\hline Khaokam Gs.no.87090 & $49^{\mathrm{A}-\mathrm{D}}$ & MS & 50 & MS & $46^{\mathrm{A}-\mathrm{D}}$ & MS & $33^{\mathrm{B}-\mathrm{D}}$ & MR \\
\hline KKU-GL-BL-05-001 & $42^{\mathrm{B}-\mathrm{D}}$ & MS & 37 & MR & $38^{\mathrm{C}-\mathrm{D}}$ & MR & $26^{\mathrm{CD}}$ & MR \\
\hline KKU-GL-BL-05-002 & $33^{\mathrm{B}-\mathrm{D}}$ & MR & 44 & MS & $45^{\mathrm{A}-\mathrm{D}}$ & MS & $35^{\mathrm{A}-\mathrm{D}}$ & MR \\
\hline KKU-GL-BL-05-003 & $31^{\text {B-D }}$ & MR & 29 & MR & $42^{\mathrm{A}-\mathrm{E}}$ & MS & $38^{\mathrm{A}-\mathrm{C}}$ & MR \\
\hline KKU-GL-BL-05-004 & $33^{\mathrm{B}-\mathrm{D}}$ & MR & 31 & MR & $32^{\mathrm{DE}}$ & MR & $31^{\mathrm{B}-\mathrm{D}}$ & MR \\
\hline KKU-GL-BL-05-005 & $42^{\mathrm{B}-\mathrm{D}}$ & MS & 43 & MR & $39^{\mathrm{A}-\mathrm{E}}$ & MR & $45^{\mathrm{A}-\mathrm{C}}$ & MS \\
\hline KKU-GL-BL-05-006 & $38^{\mathrm{B}-\mathrm{D}}$ & MR & 38 & MR & $46^{\mathrm{A}-\mathrm{D}}$ & MS & $51^{\mathrm{AB}}$ & MS \\
\hline KKU-GL-BL-05-008 & $52^{\mathrm{A}-\mathrm{D}}$ & MS & 34 & MR & $37^{\mathrm{C}-\mathrm{E}}$ & MR & $32^{\mathrm{B}-\mathrm{D}}$ & MR \\
\hline KKU-GL-BL-05-009 & $40^{\mathrm{B}-\mathrm{D}}$ & MR & 30 & MR & $40^{\mathrm{A}-\mathrm{E}}$ & MR & $28^{\mathrm{CD}}$ & MR \\
\hline KKU-GL-BL-06-010 & $31^{\mathrm{B}-\mathrm{D}}$ & MR & 37 & MR & $38^{\mathrm{B}-\mathrm{E}}$ & MR & $31^{\mathrm{B}-\mathrm{D}}$ & MR \\
\hline KKU-GL-BL-05-011 & $51^{\mathrm{A}-\mathrm{D}}$ & MS & 46 & MS & $41^{\mathrm{A}-\mathrm{E}}$ & MS & $41^{\mathrm{A}-\mathrm{C}}$ & MS \\
\hline KKU-GL-BL-06-023 & $31^{\mathrm{B}-\mathrm{D}}$ & MR & 30 & MR & $45^{\mathrm{A}-\mathrm{D}}$ & MS & $36^{\mathrm{A}-\mathrm{D}}$ & MR \\
\hline KKU-GL-BL-06-034 & $63^{\mathrm{AB}}$ & $\mathrm{S}$ & 33 & MS & $42^{\mathrm{A}-\mathrm{E}}$ & MS & $36^{\mathrm{A}-\mathrm{D}}$ & MR \\
\hline KKU-GL-BL-06-035 & $60^{\mathrm{A}-\mathrm{C}}$ & S & 42 & MS & $49^{\mathrm{A}-\mathrm{C}}$ & MS & $40^{\mathrm{A}-\mathrm{C}}$ & MR \\
\hline KKU-GL-BL-06-038 & $59^{\mathrm{A}-\mathrm{D}}$ & MS & 67 & S & $48^{\mathrm{A}-\mathrm{C}}$ & MS & $43^{\mathrm{A}-\mathrm{C}}$ & MS \\
\hline KKU-GL-BL-06-039 & $54^{\mathrm{A}-\mathrm{D}}$ & MS & 55 & MS & $42^{\mathrm{A}-\mathrm{E}}$ & MS & $42^{\mathrm{A}-\mathrm{C}}$ & MS \\
\hline KKU-GL-BL-06-041 & $65^{\mathrm{AB}}$ & $\mathrm{S}$ & 47 & MS & $44^{\mathrm{A}-\mathrm{D}}$ & MS & $39^{\mathrm{A}-\mathrm{C}}$ & MR \\
\hline KKU-GL-BL-06-043 & $64^{\mathrm{AB}}$ & S & 66 & $\mathrm{~S}$ & $48^{\mathrm{A}-\mathrm{C}}$ & MS & $54^{\mathrm{A}}$ & MS \\
\hline KKU-GL-BL-06-050 & $24^{\mathrm{D}}$ & MR & 40 & MR & $38^{\mathrm{B}-\mathrm{E}}$ & MR & $41^{\mathrm{A}-\mathrm{C}}$ & MS \\
\hline KKU-G1-B1-11-001 & $52^{\mathrm{A}-\mathrm{G}}$ & MS & 61 & $\mathrm{~S}$ & $51^{\mathrm{A}-\mathrm{C}}$ & MS & $43^{\mathrm{A}-\mathrm{C}}$ & MS \\
\hline RGDU 04285-3-3 & $46^{\mathrm{A}-\mathrm{D}}$ & MS & 51 & MS & $44^{\mathrm{A}-\mathrm{E}}$ & MS & $41^{\mathrm{A}-\mathrm{C}}$ & MS \\
\hline $\mathrm{RD6}^{1 /}$ & $76^{\mathrm{A}}$ & $\mathrm{S}$ & 51 & MS & $52^{\mathrm{AB}}$ & MS & $41^{\mathrm{A}-\mathrm{C}}$ & MS \\
\hline HY $71^{2 /}$ & $28^{\mathrm{CD}}$ & MR & 26 & MR & $29^{\mathrm{E}}$ & MR & $27^{\mathrm{CD}}$ & MR \\
\hline Average & 44.29 & & 41.04 & & 42.46 & & 37.43 & \\
\hline Maximum & 76 & & 67 & & 54 & & 54 & \\
\hline Minimum & 24 & & 23 & & 29 & & 17 & \\
\hline F-test (individual year analysis) & $* *$ & & $\mathrm{~ns}$ & & $*$ & & $* *$ & \\
\hline
\end{tabular}

${ }^{1 /}$ Susceptible genotype, ${ }^{2 /}$ Resistant genotype, ${ }^{3 /}$ Values followed by the same letter are not significantly different by Duncan's Multiple Range Test, $\mathrm{DAI}=$ days after inoculation, $\mathrm{R}=$ Resistance, $\mathrm{MR}=$ Moderate resistance, $\mathrm{MS}=$ Moderate susceptible, $\mathrm{S}=$ Susceptible, $\mathrm{ns}=$ Non-significant,$*$ and $* *$ $=$ Statistical significance at alpha level 0.05 and 0.01 , respectively

\section{DISCUSSION}

Pyricularia oryzae can cause the serious leaf blast disease in rice. Therefore, evaluation of blast resistance levels of different black glutinous rice genotypes in this study would provide more new resistant genotypes and these genotypes would also be used as the valuable germplasm for rice breeding programs in the future. Moreover, assessment the relationship between blast disease symptom at seedling and tillering stages and the relationship between blast disease symptom for the evaluation at 7 and 14 DAI would also provide the information to design the appropriate methodology for leaf blast disease screening. The results of this study indicated that higher rainfall and humidity for the screening date on September 2013 induced more severity index of leaf blast disease than the screening date on September 2014 (Table 5 and Table 6). Environmental factors such as rainfall, temperature and humidity are important for disease infections (Luo et al., 1998; Yoshihiro et al., 2014). However, the information from Table 8 indicated the maximum and minimum temperatures between 2 years were not much difference.

Statistical significance among different genotypes from combined analysis of variance was due to the fact that each rice genotype has different defense mechanisms to blast pathogens (Pattama, 1998; Wang et al., 2007; Bhuiyan et al., 2011). Considering based on both actual percentage of severity index and the resistance level across growth stages, times of evaluation and years, however, HY 71, Niawdam Gs.no.21629, Khaokam Gs.no.88084, KKU-GL-BL-05-003, KKU-GL-BL-05004, KKU-GL-BL-06-010 and KKU-GL-BL-06-023 would be recommended as high resistant genotypes when compared to the others (Table 5 and Table 6), supporting 
the first objective of this study. These resistant genotypes identified from this study would be an alternative source to support the successful of rice breeding for leaf blast resistance, especially for black glutinous rice breeding which provides the favorable cultivars for functional foods and cosmetics production (Banterng and Joralee, 2015).

Table 6. Means for severity index and resistance levels of tested rice genotypes in seedling and tillering stages and under evaluated at 7 and 14 DAI in 2014

\begin{tabular}{|c|c|c|c|c|c|c|c|c|}
\hline \multirow{3}{*}{ Genotype } & \multicolumn{4}{|c|}{ Seedling stage } & \multicolumn{4}{|c|}{ Tillering stage } \\
\hline & \multicolumn{2}{|c|}{7 DAI } & \multicolumn{2}{|c|}{14 DAI } & \multicolumn{2}{|c|}{7 DAI } & \multicolumn{2}{|c|}{14 DAI } \\
\hline & $\% \mathrm{SI}^{3 /}$ & Level & $\% \mathrm{SI}^{3 /}$ & Level & $\% \mathrm{SI}^{3 /}$ & Level & $\% \mathrm{SI}^{3 /}$ & Level \\
\hline Niawdam Gs.no.00621 & $37^{\mathrm{A}-\mathrm{F}}$ & MR & $42^{\mathrm{A}-\mathrm{C}}$ & MS & $23^{\mathrm{B}}$ & MR & $37^{\mathrm{BC}}$ & MR \\
\hline Niawdam Gs.no.09475 & $47^{\mathrm{AB}}$ & MS & $42^{\mathrm{A}-\mathrm{C}}$ & MS & $20^{\mathrm{B}}$ & MR & $55^{\mathrm{AB}}$ & MS \\
\hline Niawdam Gs.no.21427 & $43^{\mathrm{A}-\mathrm{D}}$ & MS & $41^{\mathrm{A}-\mathrm{C}}$ & MS & $21^{\mathrm{B}}$ & MR & $39^{\mathrm{BC}}$ & MR \\
\hline Niawdam Gs.no.21629 & $30^{\mathrm{B}-\mathrm{F}}$ & MR & $31^{\mathrm{C}}$ & MR & $25^{\mathrm{B}}$ & MR & $33^{\mathrm{BC}}$ & MR \\
\hline Khaokam Gs.no.88084 & $28^{\mathrm{C}-\mathrm{F}}$ & MR & $26^{\mathrm{C}}$ & MR & $25^{\mathrm{B}}$ & MR & $32^{\mathrm{C}}$ & MR \\
\hline Khaokam Gs.no. 87090 & $36^{\mathrm{A}-\mathrm{F}}$ & MR & $41^{\mathrm{A}-\mathrm{C}}$ & MS & $25^{\mathrm{B}}$ & MR & $42^{\mathrm{BC}}$ & MS \\
\hline KKU-GL-BL-05-001 & $45^{\mathrm{A}-\mathrm{C}}$ & MS & $35^{\mathrm{BC}}$ & MR & $28^{\mathrm{B}}$ & MR & $38^{\mathrm{BC}}$ & MR \\
\hline KKU-GL-BL-05-002 & $34^{\mathrm{B}-\mathrm{F}}$ & MR & $42^{\mathrm{A}-\mathrm{C}}$ & MS & $28^{\mathrm{B}}$ & MR & $30^{\mathrm{C}}$ & MR \\
\hline KKU-GL-BL-05-003 & $29^{C-F}$ & MR & $31^{\mathrm{C}}$ & MR & $29^{\mathrm{B}}$ & MR & $33^{\mathrm{BC}}$ & MR \\
\hline KKU-GL-BL-05-004 & $25^{\mathrm{EF}}$ & MR & $32^{\mathrm{C}}$ & MR & $24^{\mathrm{B}}$ & MR & $25^{\mathrm{C}}$ & MR \\
\hline KKU-GL-BL-05-005 & $30^{\mathrm{B}-\mathrm{F}}$ & MR & $34^{\mathrm{BC}}$ & MR & $28^{\mathrm{B}}$ & MR & $22^{\mathrm{C}}$ & MR \\
\hline KKU-GL-BL-05-006 & $37^{\mathrm{A}-\mathrm{F}}$ & MR & $31^{\mathrm{C}}$ & MR & $31^{\mathrm{B}}$ & MR & $38^{\mathrm{BC}}$ & MR \\
\hline KKU-GL-BL-05-008 & $36^{\mathrm{A}-\mathrm{F}}$ & MR & $31^{\mathrm{C}}$ & MR & $24^{\mathrm{B}}$ & MR & $35^{\mathrm{BC}}$ & MR \\
\hline KKU-GL-BL-05-009 & $34^{\mathrm{B}-\mathrm{F}}$ & MR & $38^{\mathrm{BC}}$ & MR & $25^{\mathrm{B}}$ & MR & $23^{\mathrm{C}}$ & MR \\
\hline KKU-GL-BL-06-010 & $31^{\mathrm{B}-\mathrm{F}}$ & MR & $31^{\mathrm{C}}$ & MR & $24^{\mathrm{B}}$ & MR & $32^{\mathrm{C}}$ & MR \\
\hline KKU-GL-BL-05-011 & $39^{\mathrm{A}-\mathrm{E}}$ & MR & $42^{\mathrm{A}-\mathrm{C}}$ & MS & $28^{\mathrm{B}}$ & MR & $35^{\mathrm{BC}}$ & MR \\
\hline KKU-GL-BL-06-023 & $27^{\mathrm{D}-\mathrm{F}}$ & MR & $34^{\mathrm{BC}}$ & MR & $24^{\mathrm{B}}$ & MR & $33^{\mathrm{BC}}$ & MR \\
\hline KKU-GL-BL-06-034 & $33^{\mathrm{B}-\mathrm{F}}$ & MR & $40^{\mathrm{BC}}$ & MR & $33^{\mathrm{B}}$ & MR & $36^{\mathrm{BC}}$ & MR \\
\hline KKU-GL-BL-06-035 & $37^{\mathrm{A}-\mathrm{F}}$ & MR & $27^{\mathrm{C}}$ & MR & $27^{\mathrm{B}}$ & MR & $41^{\mathrm{BC}}$ & MS \\
\hline KKU-GL-BL-06-038 & $46^{\mathrm{A}-\mathrm{C}}$ & MS & $33^{\mathrm{BC}}$ & MR & $23^{\mathrm{B}}$ & MR & $38^{\mathrm{BC}}$ & MR \\
\hline KKU-GL-BL-06-039 & $35^{\mathrm{A}-\mathrm{F}}$ & MR & $36^{\mathrm{BC}}$ & MR & $28^{\mathrm{B}}$ & MR & $36^{\mathrm{BC}}$ & MR \\
\hline KKU-GL-BL-06-041 & $40^{\mathrm{A}-\mathrm{E}}$ & MR & $51^{\mathrm{AB}}$ & MS & $22^{\mathrm{B}}$ & MR & $36^{\mathrm{BC}}$ & MR \\
\hline KKU-GL-BL-06-043 & $37^{\mathrm{A}-\mathrm{F}}$ & MR & $41^{\mathrm{A}-\mathrm{C}}$ & MS & $29^{\mathrm{B}}$ & MR & $32^{\mathrm{C}}$ & MR \\
\hline KKU-GL-BL-06-050 & $37^{\mathrm{A}-\mathrm{F}}$ & MR & $37^{\mathrm{BC}}$ & MR & $31^{\mathrm{B}}$ & MR & $44^{\mathrm{BC}}$ & MS \\
\hline KKU-G1-Bl-11-001 & $33^{\mathrm{B}-\mathrm{F}}$ & MR & $40^{\mathrm{BC}}$ & MR & $21^{\mathrm{B}}$ & MR & $36^{\mathrm{BC}}$ & MR \\
\hline RGDU 04285-3-3 & $36^{\mathrm{A}-\mathrm{F}}$ & MR & $33^{\mathrm{C}}$ & MR & $25^{\mathrm{B}}$ & MR & $24^{\mathrm{C}}$ & MR \\
\hline RD6 $^{1 /}$ & $51^{\mathrm{A}}$ & MS & $58^{\mathrm{A}}$ & MS & $68^{\mathrm{A}}$ & $S$ & $72^{\mathrm{A}}$ & $\mathrm{S}$ \\
\hline HY $71^{2 /}$ & $21^{\mathrm{F}}$ & MR & $29^{C}$ & MR & $26^{\mathrm{B}}$ & MR & $30^{\mathrm{C}}$ & MR \\
\hline Average & 35.50 & & 36.75 & & 27.32 & & 35.96 & \\
\hline Maximum & 51 & & 58 & & 68 & & 72 & \\
\hline Minimum & 21 & & 26 & & 20 & & 22 & \\
\hline F-test (individual year analysis) & $* *$ & & $* *$ & & $* *$ & & $* *$ & \\
\hline
\end{tabular}

Table 7. Correlation coefficients between the severity indices evaluated at 7 and 14 DAI $(n=84)$.

\begin{tabular}{|c|c|c|c|c|c|c|}
\hline \multirow[b]{2}{*}{ Year } & \multirow[b]{2}{*}{ Growth stage } & \multirow[b]{2}{*}{$\begin{array}{l}\text { Evaluation } \\
\text { date }\end{array}$} & \multicolumn{2}{|c|}{2013} & \multicolumn{2}{|c|}{2014} \\
\hline & & & $\begin{array}{c}\begin{array}{c}\text { Seedling } \\
\text { stage }\end{array} \\
\text { 14DAI }\end{array}$ & $\begin{array}{c}\begin{array}{c}\text { Tillering } \\
\text { stage }\end{array} \\
\text { 14 DAI }\end{array}$ & $\begin{array}{c}\begin{array}{c}\text { Seedling } \\
\text { stage }\end{array} \\
\text { 14 DAI }\end{array}$ & $\begin{array}{c}\begin{array}{c}\text { Tillering } \\
\text { stage }\end{array} \\
\text { 14 DAI }\end{array}$ \\
\hline \multirow[t]{2}{*}{2013} & Seedling stage & 7 DAI & $0.50^{\text {** }}$ & & & \\
\hline & Tillering stage & $7 \mathrm{DAI}$ & & $0.34^{* *}$ & & \\
\hline \multirow{2}{*}{2014} & Seedling stage & $7 \mathrm{DAI}$ & & & $0.50^{* *}$ & \\
\hline & Tillering stage & $7 \mathrm{DAI}$ & & & & $0.50^{* *}$ \\
\hline
\end{tabular}


The interaction $(p<0.05)$ between growth stage and genotype for severity index evaluated at 7 DAI (Table 3) indicated that there were different expressions of genotypes in each growth stage. At 7 DAI, therefore, screening for leaf blast at only seedling stage may not enough to identify resistant genotypes. Also, the weak relationship between severity indices of leaf blast disease evaluated at seedling and tillering stages (Table 4) indicated that evaluation the symptom of this disease only at seeding stage may not be sufficient to identify resistant genotypes, and other evaluation such as at tillering stage is necessary to determine the validity of the expression of leaf blast and to obtain more accurate result. Screening at tillering stage should be done as additional approach. This information supported the second objective of this study.

Table 8. Total rainfall, means for minimum and maximum temperatures and relative humidity during April to October in 2013 and 2014 at the Agronomy Farm, Khon Kaen University, Thailand.

\begin{tabular}{|c|c|c|c|c|c|c|c|c|}
\hline \multirow[t]{2}{*}{ Month } & \multicolumn{2}{|c|}{$\begin{array}{c}\text { Rainfall } \\
(\mathbf{m m})\end{array}$} & \multicolumn{2}{|c|}{$\begin{array}{c}\text { Maximum } \\
\text { temperature }\left({ }^{\circ} \mathrm{C}\right)\end{array}$} & \multicolumn{2}{|c|}{$\begin{array}{c}\text { Minimum } \\
\text { temperature }\left({ }^{\circ} \mathrm{C}\right)\end{array}$} & \multicolumn{2}{|c|}{$\begin{array}{c}\text { Relative humidity } \\
(\%)\end{array}$} \\
\hline & 2013 & 2014 & 2013 & 2014 & 2013 & 2014 & 2013 & 2014 \\
\hline May & 99 & 105 & 36.9 & 36.1 & 25.6 & 25.6 & 68 & 69 \\
\hline June & 99 & 130 & 33.7 & 34.8 & 25.1 & 25.7 & 73 & 76 \\
\hline July & 154 & 216 & 32.9 & 32.7 & 24.6 & 25.0 & 78 & 80 \\
\hline August & 76 & 269 & 32.6 & 32.7 & 24.4 & 24.3 & 78 & 80 \\
\hline September ${ }^{1 /}$ & 268 & 192 & 31.2 & 32.1 & 24.1 & 24.1 & 83 & 80 \\
\hline October & 43 & 31 & 30.7 & 31.2 & 22.0 & 22.8 & 73 & 74 \\
\hline
\end{tabular}

${ }^{1 /}$ Inoculation and screening in September 2013 and 2014.

Pyricularia oryzae germ cell can spread to other rice cells within 2 to $6 \mathrm{DAI}$ and the disease cycle is about 7 to 14 DAI (Cécile et al., 2008). There were both single and multiple screening during disease cycle (Puri et al., 2009; Yun Sung and Ki Deok, 2009; Zakira et al., 2009; Bhuiyan et al., 2011; Vikas et al., 2011; Shirasawa et al., 2012; Zhan et al., 2012; Aram et al., 2013a; Aram et al., 2013b). The results from this study also indicated that the correlation coefficients between severity indices of the leaf blast disease evaluated at 7 and 14 DAI were statistical significance. However, most of the correlation coefficients indicated moderate relationship between the two periods of evaluation (Table 7). Based on our result, therefore, the assessment of the severity index of leaf blast disease both in 7 and 14 DAI should be done in order to receive more perfect result for rice leaf blast screening.

\section{ACKNOWLEDGEMENTS}

This study was supported by Khon Kaen University, Thailand. Assistance in conducting the work was also received from the Plant Breeding Research Center for Sustainable Agriculture, Khon Kaen University. Acknowledgement is extended to the Thailand Research Fund (Project code: IRG5780003) and Faculty of Agriculture, Khon Kaen University for providing financial support for manuscript preparation activities.

\section{LITERATURE CITED}

Aram, P., B.J. Nadali, B. Nadali and N. Gorbanali. 2013a. Evaluation of rice genotypes for resistance to blast isolates IRAN-47 in greenhouse. Int. J. Agri. Res. Rev. 3(4): 934940.

Aram, P., B.J. Nadali, B. Nadali and N. Gorbanali. 2013b. Leaf blast resistance of rice different genotypes in blast nursery. Int. J. Agri. Crop Sci. 5(12): 1307-1313.

Banterng, P. and A. Joralee. 2015. Evaluation of black glutinous rice genotypes for stability of gamma oryzanol and yield in tropical environments. Turk. J. Field Crops 20(2): 142-149.
Bhuiyan, M.A.R., M.K. Narimah, H. Abdul Rahim, M.Z. Abdullah and R. Wickneswari. 2011. Transgressive variants for red pericarp grain with high yield potential derived from Oryza rufipogon $\times$ Oryza sativa: Field evaluation, screening for blast disease, QTL validation and background marker analysis for agronomic traits. Field Crop Res. 121: 232-239.

Bonman, J.M. 1992. Rice blast. In: Compendium of rice diseases, ed. Webster, R.K. and Gunnel, P.S., 14-16, The American Phytopathological Society, St. Paul, Minnesota, USA.

Boonsit, P., P. Pongpiachan, S. Julsrigival and D. Karladee. 2010. Gamma oryzanol content in glutinous purple rice landrace varieties. C.M.U. J. Nat. Sci. 9(1): 151-157.

Cécile, R., H. Judith, B. Sandrine, T. Didier, N. Jean-Loup, L. Marc-Henri and M. Jean-Benoit. 2008. Susceptibility of rice to the blast fungus, Magnaporthe grisea. J. Plant Physiol. 165(1): 114-124.

Chun, J. A., S. Li, Q. Wang, W.-S. Lee, E.-J. Lee, N. Horstmann, H. Park, T. Veasna, L. Vanndy, K. Pros and S. Vang. 2016. Assessing rice productivity and adaptation strategies for Southeast Asia under climate change through multi-scale crop modeling. Agr. Syst. 143: 14-21.

Cicero, A.F.G. and A. Gaddi. 2001. Rice bran oil and $\gamma$-oryzanol in the treatment of hyperlipoproteinemias and other conditions. Phytother. Res. 15: 277-289.

Freed, R.D. and O. Nissen. 1992. MSTAT-C Version 1.42. Michigan State University, East Lansing, Michigan, USA

Gomez, K.A. and A.A. Gomez. 1984. Statistical Procedures for Agricultural Research. John Wiley and Sons, New York, USA.

Hwang, B.K., Y.J. Koh and H.S. Chung. 1987. Effects of AdultPlant resistance on blast severity and yield of rice. Plant Dis. 71: 1035-1038.

International Rice Research Institute. 1996. Standard Evaluation System for Rice. 4. ed. Genetic Resources Center, International Rice Research Institute, Manila, Philippines.

Joralee, A., P. Banterng and W. Kaewpradit. 2013. Evaluation of agronomic traits and gamma oryzanol content in black glutinous rice grown under upland condition. Khon Kaen Agric. J. (Supplement) 41: 618-623. 
Karthikeyan, V. and S. Gnanamanickam. 2008. Biological control of Setaria blast (Magnaporthe grisea) with bacterial strains. Crop Prot. 27: 263-267.

Kato, H., T. Sasaki and Y. Koshimizu. 1969. Potential for conidium formation of Pyricularia oryzae in lesions on leaves and panicles of rice. Phytopathology 60: 608-612.

Luo, Y., P.S. Teng, N.G. Fabellar and D.O. TeBeest. 1998. The effects of global temperature change on rice leaf blast epidemics: a simulation study in three agroecological zones. Agric. Ecosyst. Environ. 68: 187-196.

Mackill, D.J. and J.M. Bonman. 1986. New host of Pyricularia oryzea. Plant Dis. 70: 125-127.

Obilo, O.P., A.E. Daniel, G.O. Ihejirika, M.O. Ofor and N.C. Adikuru. 2012. Control of rice blast (Magnaporthe grisea) disease using various organic manures. Int. J. Agric. Rural Dev. 15: 1198-1205.

Prabavathy, V.R., N. Mathivanan and K. Murugesan. 2006. Control of blast and sheath blight diseases of rice using antifungal metabolites produced by Streptomyces sp. PM5. Biol. Control 39: 313-319.

Puri, K.D., S.M. Shrestha, G.B.K. Chhetri and K.D. Joshi. 2009. Leaf and neck blast resistance reaction in tropical rice line under green house condition. Euphytica 165: 523-532.

Pattama, S. 1998. Mapping gene controlling blast resistance in rice (Oryza sativa L.). Ph.D. Thesis. Kasetsart University, Bangkok, Thailand.

Roumen, E.C., J.M. Bonman and J.E. Parlevliet. 1992. Leaf age related partial resistance to Pyricularia oryzae in tropical lowland rice cultivars as measured by the number of sporulating lessions. Phytopathology 82: 1414-1417.

Ryu, S.N., S.Z. Park and C.T. Ho. 1998. High performance liquid chromatographic determination of anthocyanin pigments in some varieties of black rice. J. Food Drug Anal. 6: 729-736.

Sanmuangchin, N., P. Banterng and A. Chawna. 2008 Evaluation of black glutinous rice varieties. Khon Kaen Agric. J. (Supplement) 36: 56-64.

Shirasawa, H., M. Ueno, J. Kihara and S. Arase. 2012. Protective effect of red light against blast disease caused by Magnaporthe oryzae in rice. Crop Prot. 39: 41-44.

Skamnioti, P. and S.J. Gurr. 2009. Against the grain: safeguarding rice from rice blast disease. Trends Biotechnol 27(3): 141-150.

Spyridon, D.K., K. Dimitrios, A.N. Dimitrios and L. Elisabetta. 2009. Blast disease influence on agronomic and quality traits of rice varieties under Mediterranean conditions. Turk J Agric. 33: 487-49

Talbot, N.J. 2003. On the trail of a cereal killer: exploring the biology of Magnaporthe grisea. Ann. Rev. Microbiol. 57: 177-202.

Tendulkar, S., Y.K. Saikumari, V. Patel, S. Raghotama, T.K. Munshi, P. Balaram and B.B. Chattoo. 2007. Isolation, purification and characterization of an antifungal molecule produced by Bacillus licheniformis BC 98 , and its effect on phytopathogen Magnaporthe grisea. Appl. Microbiol. 1: 2331-2339.

Teng, P.S. 1994. The epidemiological basis for blast management. In: Rice Blast Disease, ed. Zeigler, R.S., Leung, S. and Teng, P.S., 408-433, CAB International. Manila and Linden Drive, Philippines.

Theeraamphon, C. 2008. Introgression of rice blast resistance into the rice cultivar RD 6 using marker assisted selection. $\mathrm{Ph} . \mathrm{D}$. Thesis in agronomy science, Khon Kaen University, Khon Kaen, Thailand.

Vikas, K.S., A. Singh, S.P. Singh, R.K. Ellur, V. Choudhary, S. Sarkel, D. Singh, S.G. Krishnan, M. Nagarajan, K.K. Vinod, U.D. Singh, R. Rathore, S.K. Prashanthi, P.K. Agrawal, J.C .Bhatt, T. Mohapatra, K.V. Prabhu and A.K. Singh. 2012. Incorporation of blast resistance into "PRR78", an elite Basmati rice restorer line, through marker assisted backcross breeding. Field Crop Res. 128: 8-16.

Yokoyama, S. 1981. Integrated management of rice blast disease. Plant Prot. Jpn. 35:26-31.

Yoshihiro, T., M.E. Mohsen, H. Naglaa and H. Mitsuro. 2014. A novel method for controlling rice blast disease using fanforced wind on paddy fields. Crop Prot. 63: 68-75.

Yun Sung, K. and K. Ki Deok. 2009. Evidence of a potential adaptation of Magnaporthe oryzae for increased phosphorothiolate-fungicide resistance on rice. Crop Prot. 28: 940-946.

Wang, Z., Y. Jia, H. Lin, I. Adair, V. Barbara and J.N. Rutger. 2007. Host active defense responses occur within 24 hours after pathogen inoculation in the rice blast system. Rice Science 14(4): 302-310.

Zakira, N., A.H. Price, F.Y. Hafeez and M.R. Roberts. 2009. Identification of rice blast disease-suppressing bacterial strains from the rhizosphere of rice grown in Pakistan. Crop Prot. 28: 1052-1060.

Zhan, X.D., H.P. Zhou, R.Y. Chai, J.Y. Zhuang, S.H. Cheng and L.Y. Cao. 2012. Breeding of R8012, a rice restorer line resistant to blast and bacterial blight through marker-assisted selection. Rice Science 19(1): 19-35. 